\title{
Risk Imposition and Liability to Defensive Harm
}

\author{
Helen Frowe ${ }^{1}$ (D)
}

Accepted: 6 July 2021 / Published online: 18 July 2021

(c) The Author(s) 2021

\begin{abstract}
According to Jonathan Quong's moral status account of liability to defensive harm, an agent is liable to defensive harm only when she mistakenly treats others as if their moral status is diminished (for example, as if they lack a right that they in fact possess). Quong argues that, by the lights of the moral status account, a conscientious driver (Driver) who faultlessly threatens to kill Pedestrian is not liable to defensive harm. Quong argues that Driver's action is evidence-relative permissible, despite the risks it imposes, because the general practice of prudent driving is permissible. The practice is permissible because (a) its risks do not disproportionately fall on some groups rather than others, (b) the threatened harms are incidental, and (c) the risk that driving imposes is acceptable in light of the benefits everyone derives from driving. Because the correct moral theory tells us that prudent driving is permissible, Pedestrian lacks a right that Driver refrain from driving. Hence, Driver does not, by driving, treat Pedestrian as lacking a right that Pedestrian in fact possesses. Driver is not liable to defensive force. I argue, against Quong, that cost-benefit analyses of types of risky activity cannot justify individual tokens of risk imposition. Actions that risk incidentally harming others must be justified by the prospective benefits of that token action. Hence, Driver's imposition of risk on Pedestrian cannot be justified by the benefits of the general practice of driving. I argue that the permissibility of Driver's imposing risk on Pedestrian via prudent driving turns on whether Driver is willing to internalise at least the foreseeable costs of that risky action. One can lack a right that a person refrain from performing a risky action whilst possessing a right not to be harmed by that risky action. Even if Pedestrian cannot reasonably demand that Driver refrain from driving, she can reasonably demand that Driver refrain from forcing her to bear the costs of his driving.
\end{abstract}

Keywords Liability to defensive harm · Risk imposition · Jonathan Quong · Evidence-relative justification · Self-defence

Helen Frowe

helen.frowe@philosophy.su.se

1 Department of Philosophy, Stockholm University, Stockholm, Sweden 


\section{Introduction}

In his rich and challenging new book, Jonathan Quong argues that an action renders its author, A, liable to defensive harm only when (a) the evidence-relative permissibility of A's action depends on the assumption that at least one person, B, lacks a moral right, but (b) B in fact possesses the relevant moral right, and thus (c) B faces a threat, or apparent threat, to her rights ${ }^{1}$ (38). Quong calls this the moral status account of liability to defensive harm. Its moral force comes from the wrongness of A's mistakenly treating B as if B's moral status is diminished. Such treatment falls short of treating B with the "concern and respect" she is due. We make ourselves liable to defensive harm when, and only when, we treat others in this way (45).

Quong argues that if the moral status account is correct, then Resident in Mistaken Attacker is liable to defensive harm.

Mistaken Attacker: The identical twin brother of a notorious serial killer is driving during a stormy night in a remote area when his car breaks down. Unaware that his brother has recently escaped from prison and is known to be hiding in this same area, he knocks on the door of the nearest house, seeking to phone for help. On opening the door, Resident justifiably believes the harmless twin is the killer. Resident has been warned by the authorities that the killer will certainly attack anyone he meets on sight, and so Resident lunges at him with a knife. ${ }^{2}$

However, Driver in Conscientious Driver is not liable to defensive harm.

Conscientious Driver: Driver, who always keeps his car well maintained and always drives carefully and alertly, decides to drive to the movies. On the way a freak accident occurs that causes his car to veer out of control towards Pedestrian. The out-of-control car will now kill Pedestrian unless Pedestrian destroys the car with a grenade, thereby killing Driver. ${ }^{3}$

These verdicts reflect Quong's distinction between two types of evidence-relative permissibility. In some cases, such as Mistaken Attacker, an action is evidencerelative permissible only because the agent's evidence supports the belief that the prospective victim "has lost his standing to press claims against us, or at least that his claims have less weight" (38). The permissibility of Resident's threat to Twin depends on Resident's assumption that Twin is liable to be killed (48, 93). Since Twin is not so liable, Resident thereby fails to accord Twin the respect he deserves.

In other cases, such as Conscientious Driver, an action is evidence-relative permissible because the correct moral theory tells us that it may be performed despite the risks it imposes.

\footnotetext{
1 Jonathan Quong, The Morality of Defensive Force (New York: Oxford University Press, 2020). All intext citations are to this work.

2 Jeff McMahan, 'The Basis of Moral Liability to Defensive Killing' (2005) Philosophical Issues 15, p. 387.

3 McMahan, 'The Basis of Moral Liability to Defensive Killing', p. 393.
} 
Since Driver has this type of evidence-relative justification for driving, he does not, by driving, mistakenly treat Pedestrian as lacking a right that she possesses. Rather, Pedestrian in fact lacks a right that Driver refrain from driving.

Quong argues that Driver's action is evidence-relative permissible because the general practice of prudent driving is permissible. The practice is permissible because (a) its risks do not disproportionately fall on some groups rather than others, (b) the harms are incidental, and (c) the risk that driving imposes is acceptable in light of the benefits everyone derives from driving (35, see also n. 30; 157, 159). Moreover, all members of at least industrialised societies benefit from prudent driving to a roughly equal degree; "even those people who don't own cars derive significant benefits from the practice of prudent driving: they rely on others (family, friends, and bus drivers) to drive them places, they receive goods and services that are delivered by trucks, and they derive major benefits from local and global economies that are heavily reliant on the practice of driving" (35-36).

In such cases, the rights of prospective victims "have been taken fairly into account in determining that the action is evidence-relative permissible" (38). Since "the best moral theory" tells us that driving is permissible, despite the foreseeable harms, "it is unreasonable to hold individual prudent drivers liable to defensive harm for the particular harms that result from their driving" (36). Quong argues that Pedestrian may nevertheless defend herself against Driver. Quong believes that we each have an agent-relative prerogative to defensively harm non-liable people to save ourselves, provided that we do not wrongly use them as a means. But, since Driver also has such an agent-relative prerogative, he may kill Pedestrian to prevent her from defending herself. ${ }^{4}$

In Section Two, I argue that cost-benefit analyses of types of risky activity cannot justify individual tokens of risk imposition. Actions that risk incidentally harming others must be justified by the prospective benefits of that token action. In Section Three, I argue that, other things being equal, actions that incidentally impose equal risks for the sake of equal benefits are on a moral par. In Section Four, I argue that the permissibility of an agent's imposing risk on others can turn on whether she is willing to internalise at least the foreseeable costs of that risky action. ${ }^{5}$ One can lack a right that a person refrain from performing a risky action whilst possessing a right not to be harmed by that risky action. Even if Pedestrian cannot reasonably demand that Driver refrain from driving, she can reasonably demand that he refrain from forcing her to bear the costs of his driving. Section Five concludes.

\footnotetext{
4 I criticise Quong's claims about agent-relative prerogatives to impose defensive harm in Helen Frowe, 'The Limited Use View of the Duty to Save' in Peter Vallentyne, David Sobel, and Steven Wall (eds), Oxford Studies in Political Philosophy vol. 7 (New York: Oxford University Press, 2021) pp. 66-99.

5 I remain neutral here on the issue of unforeseeable costs.
} 


\section{Risky Activities}

Quong argues that, in general, "when a type of act-like the act of careful and conscientious driving poses a sufficiently low ex ante chance of harming others, it may not be reasonable to demand that others refrain from performing the act" (164). What is reasonable is determined, in part, by the evidence available to the agent who performs the harmful act.

This is why, for example, A has no right that B refrain from flipping a light switch even if, unbeknownst to B, flipping the switch will cause an explosion that will badly burn A (as in Day's End, 153). B cannot distinguish between harmful and harmless instances of light-switch flipping. Complying with a duty not to harm A would therefore require B to consistently refrain from turning on lights. Since any particular flipping has only a tiny chance of being harmful, it is not reasonable for A to demand that B consistently refrain from flipping light switches. Quong claims that "a similar story can be told for many everyday acts that impose very small risks of harm on others, but from which all, or many of us, derive substantial benefits (e.g. careful and conscientious driving, air travel)" (157). It is, he claims, "not reasonable to demand that individuals refrain from carefully and conscientiously driving their cars since the very small chance such acts may cause harm is outweighed by the benefits all of us derive from permitting this activity" (159). I'll argue here that we should reject this form of justification for risk imposition.

We can begin by distinguishing between instrumental and incidental risk imposition. A risk is instrumentally imposed when either the risk or the harm is (intended to be) constitutive of, or a means of securing, a goal. Russian Roulette exemplifies the first kind of instrumental risk imposition, where the risk imposition constitutes the goal. Risk imposition is the point of Russian Roulette. Resident's imposition of risk on Twin in Mistaken Attacker exemplifies the second kind of instrumental risk imposition. The risk of harm that Resident imposes on Twin is not a side-effect of an action intended to save Resident's life. It is, rather, the means by which Resident seeks to save his own life.

A risk is incidentally imposed when neither the risk nor the harm is constitutive of, or a means of securing, the intended goal. Driver incidentally imposes risk on Pedestrian as he drives to the movies. Imposing risk on Pedestrian is a side-effect of securing the benefit of seeing the film. It is not a means of seeing the film (her absence would not undermine Driver's ability to see the film), nor the point of driving. My arguments here apply only to incidental risk imposition.

We saw in Section One that Quong is careful to explain how even non-drivers benefit from prudent driving, since, in his view, the permissibility of Driver's action is grounded in how risks and benefits are distributed across this particular category of activity. But this seems wrongheaded. The incidental imposition of a risk of a morally significant harm is justified by the good for which that particular risk is imposed, and not by whether the risk-imposing activity is of a certain type. In Day's End, for example, B is evidence-relative justified in flipping the light switch, even if his evidence is that it risks harming $\mathrm{A}$, because that risk is so 
tiny. Imposing a tiny risk can be justified by the prospect of even a trivial benefit to B. We turn on lights to obtain a variety of benefits of varying importance: for example, more safely and efficiently carrying out useful tasks, creating an ambience, reducing the risk of accidents, and avoiding the unpleasantness of sitting in the dark. Even the sheer entertainment factor of otherwise pointlessly flipping a switch on and off counts as a benefit. But the benefits relevant to justifying B's flipping the light switch are limited to those that might result from B's flipping the light switch. They do not include benefits that might result from other instances of flipping light switches.

Quong's view, in contrast, holds that B's action can be justified by the benefits that accrue from, for example, permitting surgeons to turn on lights to perform life-saving operations. What matters is the 'type' of act that B performs (159), and whether the overall practice of 'light switch flipping' is justified despite the concomitant risks. As Quong argues with respect to driving, "the act of careful and conscientious driving is justified [primarily] because the probability of harming an innocent person is extremely low, but the benefits of permitting the practice are very large" (47, emphasis added). Quong's evidence-relative justification is thus strangely asymmetrical. The relevant risk is indexed to the particular instance of driving. If, for example, the road is dangerously icy, Driver cannot justify driving on the grounds that driving in general is low risk. To say that his driving is prudent just is to say that this particular journey is very low risk. And yet, whilst the risks relevant to Driver's evidence-relative justification are limited to those of Driver's particular journey, Quong argues that the benefits relevant to the evidence-relative justification are those that result from the entire practice of prudent driving. (Indeed, set against these substantial benefits, one might wonder why only low risk journeys are justified.)

I suggest that the risks that Driver and B (from Day's End) will impose can be offset only by the benefits that their own actions might produce. We can see the plausibility of this view by considering cases in which someone is permitted to take a non-trivial risk of harming A by turning on a light, such as Surgery:

Surgery: An explosion at a power station is known to be causing dangerous local surges of electricity. A surgeon at the nearby hospital can perform lifesaving surgery on $\mathrm{C}$ only if she turns on the light in the operating theatre. There is a 0.01 chance that flipping the switch will cause A moderate burns.

Let's stipulate that A would be required to incur a 0.01 chance of moderate burns to save C's life, and thus has no right against the imposition of this risk by the surgeon. The prospective benefit of this token of the activity-type 'light switch flipping' - saving C's life - has no bearing on the degree of risk that B may impose on A in Day's End. The benefits of other instances of light-switch flipping are irrelevant to B because nothing unifies 'light switch flipping' as a morally salient kind, 
just as nothing unifies prudent driving as a morally salient kind. There is, for example, no causal dependency between B's turning on the hall light and the surgeon's ability to operate that could play such a unifying role. ${ }^{6}$ At best, the performance of other instances of the activity type has epistemic value, providing evidence of how risky similar actions might be. But the benefits derived from the surgeon's action have no power to justify B's action, any more than they might justify Driver's trip to the movies.

We can derive further evidence of the irrelevance of the activity type to justification by thinking about cases in which this epistemic role about likely risk is undercut. If B has excellent evidence that a particular instance of flipping is very likely to harm A, then the activity type has no relevance at all. Other things being equal, there is no morally significant difference between B's throwing a grenade that he knows has a 0.9 chance of causing A serious burns, and B's flipping a switch that he knows has a 0.9 chance of causing A serious harm. (More on this in Section Three.)

We might reply it's too costly to regulate or monitor the purposes for which we may drive, for example, and that, given the benefits of some instances of driving, it is overall best to allow everyone to prudently drive for any reason. This means that permitting the practice of prudent driving is overall justified, and hence the risks imposed by each instance of prudent driving are justified. But this conclusion doesn't follow. The fact that it is too costly to prevent people from imposing unjustified risks does not entail that the risks they impose are justified. By way of comparison, refraining from monitoring people's reasons for driving might also be justified by their rights to privacy. But the fact that it would violate privacy to monitor people in this way does not entail that what they are doing is justified.

\section{The Moral Parity of Risky Activities}

The foregoing arguments give us reason to be sceptical of Quong's treatment of risky activities. Here, I sketch an alternative view. I suggest that when two actions incidentally impose the same degree of risk for the sake of achieving equivalent goods, the type of risky activity is irrelevant to its permissibility.

Suppose that Driver's going to the movies has a 0.00001 chance of threatening Pedestrian's life, and Driver expects to obtain the benefit of an afternoon's moderate entertainment. Say that we agree that Pedestrian has no right that Driver not expose her to that degree of risk for the sake of securing that degree of benefit. Now imagine that Rider's going horse-riding has a 0.00001 chance of threatening Pedestrian's life by Rider's faultlessly losing control of her horse. Rider expects to enjoy an afternoon's moderate entertainment.

I suggest that (a) if Pedestrian lacks a right against Driver's risk imposition, she also lacks a right against Rider's risk imposition, and (b) Driver and Rider have

\footnotetext{
6 The closest we might get is an argument that, e.g., the road and electricity networks will exist only if there is sufficient demand. But since, at least in all industrialised countries, we're well past the threshold of sufficient demand, it's hard to see how Driver or B can appeal to this kind of argument.
} 
precisely the same evidence-relative justification for imposing risk on Pedestrian. The risk they pose to her is equally tiny, and they impose it for the sake of securing equally valuable benefits. The same is true of Hunter, whose afternoon of (legal) recreational shooting poses a 0.00001 chance of incidentally harming Pedestrian. ${ }^{7}$ Driver does not have a stronger justification, compared to Rider and Hunter, for endangering Pedestrian, grounded in the benefits of public bus services and Amazon deliveries. It is arbitrary to group actions together as instances of a type for the purposes of justifying risk imposition independently of the benefits that are produced by token actions. As above, nothing ties these actions - a trip to the movies, providing a bus service, and making deliveries — together in a morally significant way. Nor does Hunter have a weaker justification for endangering Pedestrian, even if the practice of firing guns is not overall beneficial. Pedestrian does not possess a right not to be exposed to a 0.00001 risk of lethal harm by Hunter's recreational shooting if she lacks a right not to be exposed to the same risk by Driver's recreational driving.

This argument does not entail that the greater the benefit sought, the greater the risk one may impose. There is, plausibly, a limit to the risk that we may impose on others unless we are seeking to avert serious harm (I take no stand here on where that limit lies). But it does suggest that pointlessly exposing people to risks of non-trivial harms wrongs them. If B flips the light switch on and off for no reason at all-he doesn't find it even mildly amusing - then, insofar as his action foreseeably imposes a risk of nontrivial harm on others, it's evidence-relative impermissible. To see the plausibility of this view, consider that part of our objection to, say, someone's pointlessly turning on lights, or pointlessly driving, is that it harms the environment. If pointlessly causing harm is wrong, pointlessly risking harm is, plausibly, also wrong. Again, B can't point to the fact that turning on light switches is generally beneficial to justify his pointless imposition of risk on A. (If this strikes us as implausible, I suspect it's because we doubt that the harm to A really is foreseeable. But remember that we're assuming that $\mathrm{B}$ may act even if his evidence is that his action risks harming A.)

We can further support this view by considering the incidental imposition of risks in pursuit of morally bad ends. If Driver is driving to murder his wife, for example, his imposition of risk on Pedestrian for the sake of achieving this end is unjustified, no matter how prudently he drives. This doesn't mean that it is proportionate for Pedestrian to kill Driver to prevent him from wrongly imposing this tiny risk of death on her, of course. But it does mean that Driver wrongs Pedestrian. The imposition of risks of morally significant harms must be justified by the prospect of morally significant goods. We are often insensitive to this when it comes to ordinary risk-imposing activities, perhaps because we fail to realise that they are riskimposing at all, or because, as above, the risk is so small that even the slightest prospect of a small good suffices as justification. We might also think that, at least sometimes, the good of not having to do the tiresome cost-benefit analysis can justify simply proceeding with imposing very small risks. ${ }^{8}$ But this doesn't mean that

\footnotetext{
7 We might have rights against being exposed to illegal risks of harm even if the risks are on a par with other, legal risk-imposing activities, at least insofar as we have rights that others obey the law.

8 Thanks to Joseph Bowen for this suggestion.
} 
very small risks of lethal harm don't require justification. This is not a point of contention between me and Quong: after all, his argument about beneficial practices is, precisely, an attempt to show that the imposition of these very small risks of serious harm is justified. Our disagreement concerns how such risks are justified, not whether they demand justification.

\section{Internalising Costs}

\subsection{The Internalisation Model of Risk Imposition}

According to Quong, it is unreasonable for Pedestrian to demand that Driver refrain from driving because the practice of prudent driving is justified. I suggest that whether it is reasonable to demand that a person refrain from a risk-imposing activity can depend on whether she is willing to internalise the costs of her risky behaviour. If Driver is so willing, Pedestrian lacks a right that Driver refrain from prudent driving. But she nonetheless has a right not to be killed by Driver. To say otherwise is to imply that Pedestrian ought to bear the costs of Driver's risk imposition, which is unfair. Call this the internalisation model of permissible risk imposition. I focus here on self-interested risk imposition, since this is the kind of risk imposition in which Driver, Rider, Hunter, and B are engaged. ${ }^{9}$ The internalisation model rejects Quong's claim that if one lacks a right not to be exposed to a risk of harm, one must therefore lack a right not to suffer that harm (and, conversely, that if one has a right not to suffer a harm, one must therefore have a right not to be exposed to a risk of that harm) (172).

Quong's account suggests three categories of self-interested risky activities:

(i) those that are instances of overall beneficial practices against which we lack rights, such as driving;

(ii) those that are 'abnormally risky', such as owning tigers, that are permissible only if there is some mechanism for fairly distributing resultant costs (50); and

(iii) those that are 'in between' - that is, that are not overall beneficial, and so do not come under (i), and are not abnormally risky, and so do not come under (ii).

Category (iii) must be broad, comprising, for example, horse-riding, cycling, and playing frisbee in the park. It is implausible that all or most of us derive substantial benefits from the practice of prudent frisbee-playing, or that the benefits derived from frisbee-playing are even roughly shared amongst players and non-players alike.

\footnotetext{
${ }^{9}$ I do not think that only self-interested risks fall under the internalisation model, nor that all risk imposition falls under this model. I lack space to explore this here, but one possibility is that agents need not internalise the cost of risky actions when they have been appointed by other members of the moral community to perform those actions as a means of enabling us to discharge our pre-contractual moral duties. On this view (and contra Quong), a paramedic is not on a moral par with Driver.
} 
Playing frisbee in public imposes risks on both players and non-players, but secures benefits only, or certainly overwhelmingly, for players. It must be treated quite differently, on Quong's view, to recreational driving.

I've argued that we ought to reject category (i): we cannot appeal to the class of 'overall beneficial practices' to justify specific instances of risk imposition. The arguments against risky types that I offered in Sect. 2 speak equally against having a category of 'abnormally risky' activity types (category (ii)). Whilst the law might have good reason to demarcate actions that tend to impose high levels of risk, there's nothing morally special about being an instance of the type 'keeping tigers'. If keeping tigers imposes a 0.00001 chance of causing harm, the fact that it's an instance of the type 'keeping tigers' does not mark it out as nonetheless abnormally risky, and thus justifiably subject to special conditions of risk imposition.

Quong suggests that the evidence-relative permissibility of keeping tigers could depend on having, for example, a taxation system to compensate victims who are harmed by nonnegligent agents (50). But he doubts that the permissibility of actions in category (iii) similarly depends on whether the risk-takers are willing to internalise costs. Rather, if these actions are permissible, it is because others cannot reasonably demand that we refrain from them. According to the Revised Harm Thesis (156), whether A can demand that B refrain from a harmful action depends on,

a wide array of considerations, including, though not limited to, (i) the importance of the activity B engages in by $\varphi$-ing, (ii) how costly it would be for B to refrain from $\varphi$-ing, (iii) whether $B$ had sufficient opportunity to avoid finding himself in a situation where he faces the choice whether or not to $\varphi$, and (iv) whether A had sufficient opportunity to avoid finding himself in a situation where he might be harmed by B's $\varphi$-ing.

Playing frisbee is not very important (i), and B could easily refrain without incurring any significant cost (ii). Given this, the ease with which B could have avoided facing a choice to play frisbee (iii) seems irrelevant. And if A can't demand that others refrain from playing frisbee in public, it is very costly for him to avoid situations where might find himself exposed to the risks of frisbee (iv). It seems unlikely, then, that the Revised Harm Thesis permits playing frisbee in public. Of course, Quong notes that the above list is not exhaustive. I suggest that the most plausible condition that Quong might add, to justify the verdict that A cannot reasonably demand that B refrain from playing frisbee, is that B will internalise the costs of his frisbeeplaying. If so, A cannot reasonably demand that B refrain from his risky activity, but $\mathrm{B}$ lacks a right to make $\mathrm{A}$ bear the costs of his risky activity.

The internalisation model offers a unified explanation of the permissibility of a broad range of self-interested risk-imposing activities, grounded in the fact that it is generally important or beneficial that each of us be allowed to engage in at least some risk-imposing activities. A natural explanation of the permissibility of allowing such activities is that we would overly restrict our ability to live good, autonomously shaped lives if we prohibited risk imposition altogether, or allowed only risk-imposing activities that are overall beneficial for participants and non-participants alike. The best moral theory, then, might tell us that we may each engage in certain risk-imposing activities only if we are willing to bear the costs of those 
activities if they threaten or cause harm, which includes not harmfully preventing those costs from being redirected towards us.

The internalisation model thus rejects Quong's claim that someone is permitted to create a risk of harm to others to secure a benefit for herself, and then force others to bear any resultant costs of that risk. We can reasonably demand that people refrain from imposing risks when they are unwilling to bear the resultant costs and will instead try to force others to bear those costs, as Driver or Rider will if they prevent Pedestrian's defending herself. (This is, in fact, the view that McMahan proposes in his original defence of the Responsibility Account. ${ }^{10}$ )

The internalisation model is supported by widespread intuitions concerning compensation. If Bobby's car crashes into Alice's fence when its brakes fail, Bobby plausibly owes Alice compensation even if he is faultless. Alice is unlikely to be impressed by Bobby's argument that he need not pay for the damage because driving is an overall beneficial activity for participants and non-participants alike, nor, indeed, if Bobby explains that it is beneficial for all of us to be able to impose selfinterested risks. Rather, our intuitions suggest that although Bobby is permitted to prudently drive, he isn't permitted to damage Alice's fence and refuse to pay for it. It is permissible for a person to impose such risks only if they agree to bear any resultant costs. And if that's true ex post, it is plausibly true ex ante as well. Alice may proportionately damage Bobby's car in order to prevent him from damaging her fence, and she would not owe Bobby compensation for that damage.

To be clear, I am not making a claim about what the law says. There is a considerable gap between what we can owe, as a matter of morality, for having caused harm, and how laws might be (best) set up to enforce our obligations. For example, given their number, it might be impractical for a legal system to deal with all cases of incidental damage. This might justify restricting legal mechanisms to cases of negligence. But this does not settle the matter of what we owe as a matter of morality, any more than the lack of legally mandated apologies shows that nobody ever owes an apology.

\subsection{Against Internalisation}

Quong offers three reasons to reject the internalisation model. First, he denies that we can draw support for liability to defensive harm from compensatory practices since, in his view, liability to defensive harm, unlike compensation, is not about the fair distribution of costs (49). But this is, clearly, not a worry for those who do view liability to defensive harm as at least partly a matter of fair distribution of costs. Moreover, as I suggest below, liability to compensatory costs and liability to defensive harm plausibly share an underlying justification. Thus, if compensation is about the fair distribution of costs, as Quong grants, then so too is liability to defensive harm.

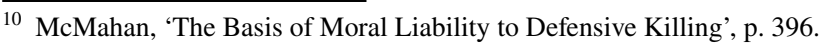


Second, Quong argues that the internalisation model will prohibit a great deal of seemingly permissible risky activity. Private law might employ a strict liability model for compensating people who are harmed by (abnormally) risky activities, making permissible risk imposition conditional on the possibility of shifting costs from victims to risk-takers. But this system crucially depends on the assumption that private law is an efficient means of fairly distributing costs (49). Suppose that only some victims have recourse to private law, and that compensation is secured in only 40 percent of cases. If the ability to shift costs is a necessary condition of permissible risk imposition, we should prohibit risk imposition in the remaining cases. And, Quong argues, defensive force is inefficient in just this way. Holding threateners liable to defensive force does not ensure that victims will be able to successfully defend themselves; many victims will not be so able. Thus, "it makes no sense to suppose that holding agents liable to defensive force is an effective way of distributing the costs of activities in a way that can render otherwise impermissibly risky activities permissible" (50).

This objection is unpersuasive because holding threateners liable to defensive force is consistent with holding them liable to pay compensatory costs. And, contra Quong, it is plausible that these types of liability have a shared explanation. If Bobby owes Alice compensation after he damages her fence, this is because Bobby must internalise the cost of his risk imposition. This same fact justifies making Bobby internalise those costs ex ante. Defensive liability and compensatory liability are two upshots of the same underlying moral claim about where costs should lie. ${ }^{11}$ We do not need to choose between a system of fair distribution ex ante or a system of fair distribution ex post. Rather, the availability to victims of ex ante and ex post distribution mechanisms - that is, the liability of risk-imposers to defensive and compensatory costs - can suffice to make a risky activity permissible, and prospective victims may avail themselves of either mechanism to avoid bearing the costs of other people's risk imposition. When Bobby hurtles towards Alice's fence, Alice may either damage Bobby's car to prevent him from damaging her fence, or she may let him damage the fence, and later claim the costs of repair.

Compensation is often unable to give victims, especially of physical harms, their preferred outcome of making things just as they were. ${ }^{12}$ This means that victims are usually justified in imposing defensive costs rather than claiming compensation. For the same reason, other things being equal, our duties to rescue require us to defend

\footnotetext{
11 For defence of similar claims, see e.g. Joseph Raz, 'Personal Practical Conflicts' in Paul Baumann and Monika Betzler (eds), Practical Conflicts: New Philosophical Essays (Cambridge: CUP, 2004), pp. 172-196; John Gardner, 'What is Tort Law For? Part 1: The Place of Corrective Justice' (2011) Law and Philosophy 30(1), pp. 1-50; John Gardner, From Personal Life to Private Law, (Oxford, Oxford University Press: 2018), p. 102; Victor Tadros, 'Secondary Duties' in John Oberdiek and Paul B. Miller (eds), Civil Wrongs and Justice in Private Law (Oxford: Oxford University Press, 2020) pp. 185-207; Sandy Steel, 'Compensation and Continuity' (2020) Legal Theory 26(3), pp. 250-276.

12 For discussion of the different ways in which compensation can offset a cost, see Adam Slavny, 'Negating and Counterbalancing: A Fundamental Distinction in the Concept of a Corrective Duty' (2014) Law and Philosophy 33(2), p. 143-173.
} 
the victim of an unjust attack rather than allow her to be harmed on the assumption that we will ensure that she is later compensated.

This gives us reason to permit victims to employ defensive force rather than requiring them to settle for compensation. It does not entail that victims may not revert to claiming compensation if defence is impossible. Provided that defence and compensation together enable us to make risk-imposers internalise the costs of their actions, it is unimportant how claims are distributed across the two mechanismsthat is, what portion of claims are satisfied by defence, and what portion by compensation. This model is compatible with a range of views about how those who might be subjected to compensation claims may distribute the burden of these claims amongst themselves. For example, they might be permitted to pool their resources in a mutual insurance scheme. We should note, though, that the permissibility of risk-imposers sharing liability to compensatory harms amongst themselves does not show that victims may not impose defensive harm on any particular risk-taker. Whereas victims plausibly have no claim to be compensated by a particular nonnegligent individual rather than a mutual scheme, they do have a claim to prevent themselves from suffering harm rather than be forced to seek compensation later. ${ }^{13}$

Contra Quong, then, the internalisation model does not permit driving only if a sufficiently high proportion of prospective victims will be able to defend themselves. Rather, it permits driving provided that a sufficiently high proportion of prospective victims have access to mechanisms that enable them to avoid bearing the (full) costs of other people's risky actions. Moreover, the internalisation model holds that Driver is not permitted to prevent Pedestrian from making him bear the costs of his risky action-that is, that Driver may not use counter-defence against Pedestrian. This will be an efficient means of ensuring that, in cases in which victims can defend themselves, they are able to make risk-imposers bear the costs of their risky activities.

Finally, Quong argues that the fact that tort law "recognizes a class of activities that are abnormally risky and subject to a strict liability standard does not necessarily support the conclusion that activities are permissible only if a strict liability standard is applied"(50). But nor does Quong offer an explanation of why normally risky activities that do not meet the standard of being overall beneficial, such as playing frisbee in the park, are permissible even if their authors refuse to internalise the costs. Why can't the reasonableness of a demand that the agent refrain from acting turn on whether she will try to force others to bear the cost of her actions? Once we pay proper attention to the distinction between a right that someone refrain from imposing a risk and a right not to be harmed, we can see that the right not to be harmed does not place unreasonable demands on others. It does not tell someone that they may never play frisbee. It tells them that they may not force other people to bear the costs of their frisbee-playing. And that seems fair enough.

Nor does the internalisation model of risk imposition hold that merely playing frisbee makes someone liable to harmed. In summarising the case for his view, Quong claims a significant advantage over the moral responsibility account of liability to

$\overline{13}$ We may, however, have a claim to be compensated by a particular person if she has wronged us. 
defensive harm. On its standard formulation, the moral responsibility account holds that a person is liable to defensive harm if she is morally responsible for an action that foreseeably risks imposing unjust harm, and that risk eventuates. ${ }^{14}$ Quong asks you to imagine casting your ballot for a political party, $\mathrm{C}$, foreseeing the very small chance that your vote will play "an important causal role in electing $\mathrm{C}$ and that $\mathrm{C}$ may go on to cause fact-relative impermissible harm", and a Red Cross doctor who can foresee that saving a soldier "may causally contribute" to that soldier's causing unjust harm (173). Quong argues that, unless it resorts to implausible claims about causal remoteness and degrees of responsibility, the moral responsibility account must "counterintuitively admit that you make yourself liable to defensive harm by casting your ballot and the doctor makes herself liable by saving the soldier" (173).

But the responsibility account does not hold that people who take risks of unjustly harming are liable to defensive force merely in virtue of taking those risks. It holds that risk-takers are liable to defensive force only when their risk will otherwise eventuate in unjust harm, and proportionate force against them will avert that harm. ${ }^{15}$ Quong presumably endorses a similar distinction regarding the defensive scope of agent-relative prerogatives. Pedestrian's agent-relative prerogative does not permit her to kill Driver to prevent him from driving - that is, to prevent Driver from exposing her to a risk of being killed. Rather, she may kill Driver only to prevent him from crashing into her-that is, to prevent him from harming her. ${ }^{16}$ If our prerogatives are sensitive to such a distinction, our rights should be similarly sensitive.

The foregoing arguments suggest that for certain risk-imposing activities, such as prudent driving, participants lack rights against bearing the foreseeable costs of those activities, and that this partly explains the permissibility of the activity. If so, we cannot point to the permissibility of prudent driving to show that it is unreasonable to make drivers bear the costs of their risky behaviour. Driver's lack of a right not to bear these costs explains why Driver may be harmed by Pedestrian and why Driver may not harm Pedestrian in counter-defence. Defensively harming Pedestrian impermissibly forces Pedestrian to bear the cost of Driver's risk imposition. Pedestrian can have a right against this without also having a right that Driver not impose the risk.

\section{Conclusion}

I have argued that the moral status account cannot support its claim that Pedestrian lacks a right not to be killed by Driver. The fact that prudent driving is an overall beneficial practice does not entail that we lack rights not to be harmed by prudent

\footnotetext{
14 See e.g. McMahan, 'The Basis of Moral Liability to Defensive Killing'. (I've dropped the claim that only this relationship can ground liability.).

15 And, on some views, will also be the least harmful means of averting the threat.

16 Given this, we need not worry about the fact that, strictly speaking, the distinction is between imposing a tiny risk of harming and imposing a very high risk of harm (since, until Driver actually hits Pedestrian, we cannot be sure that he will do so). On both accounts, Pedestrian may harm Driver only when he's otherwise (almost) certain to hit her, and not simply to prevent him from imposing the (very low) risk of doing so.
} 
drivers. In general, the incidental imposition of self-interested risks is permissible only if the risk-taker is willing to internalise at least the foreseeable resultant costs of the risky action. This means that whilst we cannot reasonably demand that others refrain from risky actions, we can reasonably demand that they do not force us to bear the costs of those actions. Pedestrian may defensively harm Driver to prevent him from forcing her to bear the cost of his risky behaviour. Since he lacks a right not to bear the costs of his risky behaviour, Driver may not harm Pedestrian in counter-defence.

Acknowledgements Thanks to Joseph Bowen, Cécile Fabre, and Jonathan Parry for helpful written comments on, and discussions of, earlier drafts.

Funding Open access funding provided by Stockholm University. Work on this paper was funded by the Knut and Alice Wallenberg Foundation, Grant Number 1521101.

Open Access This article is licensed under a Creative Commons Attribution 4.0 International License, which permits use, sharing, adaptation, distribution and reproduction in any medium or format, as long as you give appropriate credit to the original author(s) and the source, provide a link to the Creative Commons licence, and indicate if changes were made. The images or other third party material in this article are included in the article's Creative Commons licence, unless indicated otherwise in a credit line to the material. If material is not included in the article's Creative Commons licence and your intended use is not permitted by statutory regulation or exceeds the permitted use, you will need to obtain permission directly from the copyright holder. To view a copy of this licence, visit http://creativecommons.org/licen ses/by/4.0/.

Publisher's Note Springer Nature remains neutral with regard to jurisdictional claims in published maps and institutional affiliations. 